Original Research

\title{
Attitudes and behavioral intentions of aortic dissection survivors towards exercise: an application of the health action process approach framework
}

\author{
Danni Feng ${ }^{1,2}$, Sufang Huang ${ }^{1, *}$, Xiaorong Lang ${ }^{2}$ \\ ${ }^{1}$ Department of Emergency, Tongji Hospital Affiliated to Tongji Medical College, Huazhong University of Science and Technology, 430030 Wuhan, \\ Hubei, China \\ ${ }^{2}$ School of Nursing, Tongji Medical College, Huazhong University of Science and Technology, 430030 Wuhan, Hubei, China \\ *Correspondence: huangsufang@tjh.tjmu.edu.cn (Sufang Huang) \\ Academic Editors: Francesco Onorati, Brian Tomlinson and Takatoshi Kasai \\ Submitted: 14 October 2021 Revised: 12 November 2021 Accepted: 28 December 2021 Published: 15 February 2022
}

\begin{abstract}
Background: Exercise can help patients with aortic dissection (AD) control blood pressure, prevent further progression of AD, promote mental health, improve the prognosis of cardiovascular disease, and improve their overall quality of life. However, it is not clear what the attitudes and behavioral intentions of AD survivors are towards exercise. Methods: This exploratory qualitative research was based on the Health Action Process Approach (HAPA) theory to explore the cognition, attitude, motivational factors, behavior intention, barriers and facilitators of exercise in patients with AD. Face-to-face and telephone semi-structured interviews were conducted in $24 \mathrm{AD}$ patients from the Department of Cardio-Vascular Surgery of third-grade Class A hospitals in Wuhan, China from April 2021 to June 2021. The patient's current stage of behavior was evaluated according to the Patient-Centered Assessment and Counseling for Exercise (PACE) questionnaire. Results: Among the 24 participants interviewed, 9 (37.5\%) were in the pre-intention stage, $8(33.3 \%)$ were in the intention stage, and 7 (29.2\%) were in the action stage. The three groups were significantly different in terms of their history of previous cardiac surgery (Fisher's exact test, $p=0.043$ ) and in the type of interview conducted (Fisher's exact test, $p<0.001$ ). In-patients with a history of cardiac surgery were more likely to be in the pre-intention stage (post-hoc test, $p<0.05$ ). Patients from different stages had different structures. AD patients in the pre-intention stage were more likely to express risk perception and negative results for exercise. The self-efficacy of this group was often low, and lacked exercise intention and clear action plans (post-hoc test, $p<0.05$ ). Conclusions: More attention should be paid to in-patients with a history of cardiac surgery, including health advice on exercise after discharge and promotion of changes in their health behavior. Guidelines based on the available exercise data in AD patients should be established to provide recommendations for individualized exercise programs. This should provide a basis for promoting patient rehabilitation and improving postoperative quality of life.
\end{abstract}

Keywords: aortic dissection; exercise; health action process approach; attitudes; behavioral intentions

\section{Introduction}

Aortic dissection (AD) is a pathological change where the blood in the aortic cavity enters the aortic media from the aortic intima tear and expands along the long axis of the aorta, resulting in separation of the true and false aortic cavities [1]. It is a serious cardiovascular emergency with the characteristics of sudden onset, rapid progression and high mortality.

In recent years, with the improvement of diagnostic methods, surgical techniques, anesthesia and drug treatment, the postoperative outcome of AD has steadily improved [2,3]. Howard et al. [1,4] reported the 5-year survival rate of patients with $\mathrm{AD}$ was $60 \%-80 \%$. However, the medium-term prognosis is still poor and the risk of AD recurrence, rupture and cardiovascular disease is high in this group [5]. The quality of life (QoL) of AD survivors was not ideal $[6,7]$, and patients tend to have decreased physical function and some psychological problems such as anxiety and depression [8-10].
The average age of patients presenting with acute AD ranges from age 48 to 67 years (median age, 61) [11], with survivors now often being younger and more physically active [12]. As such, this patient group often desires a high quality of life. The most important factor following AD diagnosis is to control the patient's blood pressure [1]. Moderate physical exercise is an important intervention to lower blood pressure, prevent the progression of $\mathrm{AD}$, promote mental health, and improve the prognosis and overall quality of life of the AD patient [13-15]. A recent review established the safety and effectiveness of exercise-based cardiac rehabilitation for AD patients [16]. Moderate and low intensity aerobic exercise such as fast walking or cycling (3-5 Metabolic equivalents) for $\geq 30$ minutes and for at least 150 minutes per week can help patients to better control arterial blood pressure and improve cardiovascular health [17].

Conceptual models or theories can provide a useful basis for exploratory research [18]. Schwarzer put forward the theory of Health Action Process Approach (HAPA) in 


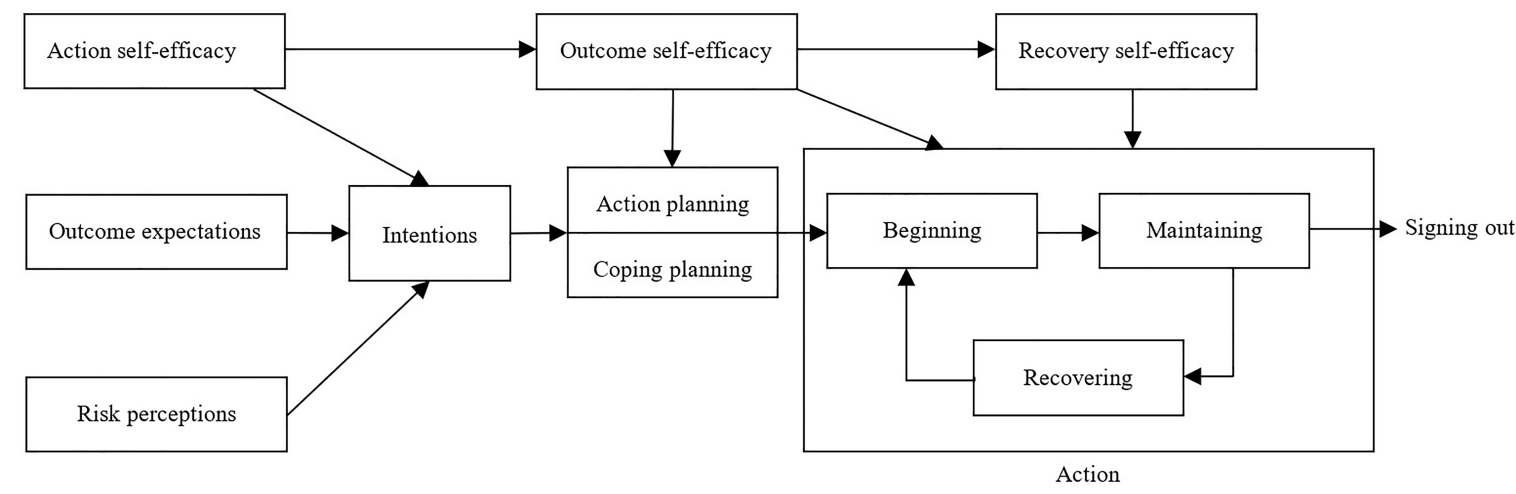

Motivation phase

Volition phase

Fig. 1. Health Action Process Approach (HAPA) mode. Schwarzer put forward the theory of HAPA in 1992 [19]. In HAPA, the change of healthy behavior is regarded as a continuous change process including the beginning, maintenance and recovery of behavior. Behavioral intention, as an important predictor of health behavior, is the core of the theoretical model.

1992 [19]. In HAPA, the change of healthy behavior is regarded as a continuous change process that includes the beginning, maintenance and recovery of behavior. The theoretical framework of the model is shown in Fig. 1 (Ref. [19]). Some scholars have applied HAPA theory to patients with persistent musculoskeletal pain [20] or following lung cancer surgery [21] in order to explore the cognitive and behavioral characteristics of individuals in the process of exercise behavior change.

In view of the sparse research published to date on the attitude to exercise in postoperative patients with $\mathrm{AD}$, here we performed qualitative research on the exercise behavior of AD patients. Based on the HAPA theory, we explored the cognition, attitude, motivational factors, behavior intention, barriers and facilitators of exercise in patients with AD.

\section{Methods}

\subsection{Study design}

A qualitative study design and content analysis approach was implemented.

\subsection{Participants}

The method of purposive sampling was employed. When there were no new views in the structure of cognition, attitude, motivational factors, behavior intention, barriers and facilitators of exercise during the interview of patients with $\mathrm{AD}$, this indicated the sample size had reached saturation and no further interviews were required [22]. Thirty survivors of $\mathrm{AD}$ were recruited from the Department of Cardio-Vascular Surgery of third-grade Class A hospitals in Wuhan, China. Six survivors refused to participate in the study because of a lack of time or interest. Of the remaining 24 patients, 12 in-patients were interviewed faceto-face and 12 discharged patients were interviewed by telephone. Inclusion criteria included: (1) patients were diag- nosed according to the 2014 European Society of Cardiology guidelines; (2) age $\geq 18$ years; (3) patients were in a stable condition and had stable vital signs with no serious complications; (4) voluntary participation; and (5) patients with the ability to understand and communicate in language or words. Exclusion criteria included: (1) patients with psychiatric illnesses, cognitive disorders or who were comatose; and (2) patients who were still in an unstable condition and needed further care.

\subsection{Data collection}

Data was collected from April 2021 to June 2021 by a graduate student with training in qualitative research methodology (DNF). Eligible patients were selected following the doctor's ward rounds. Contact information for discharged patients was obtained from the doctors' workstation. Informed consent from patients was obtained after fully explaining the purpose of the study. General information on patients with AD was obtained from the medical records according to their hospitalization number. The patient's current stage of behavior was assessed according to the Patient-Centered Assessment and Counseling for Exercise (PACE) questionnaire [23]. The interview outline was drawn up based on the HAPA theory. After the preinterview, the final version of the interview outline was modified and determined according to the interview results and the patient's response, as shown in Fig. 2. The interview lasted 20-40 min and was conducted in a quiet, comfortable and closed location. The patients were in an office, while the telephone interviews were conducted in quiet rooms. Only the interviewer and interviewee participated. The interview was audio-recorded with field notes taken. No repeat interviews were conducted. 


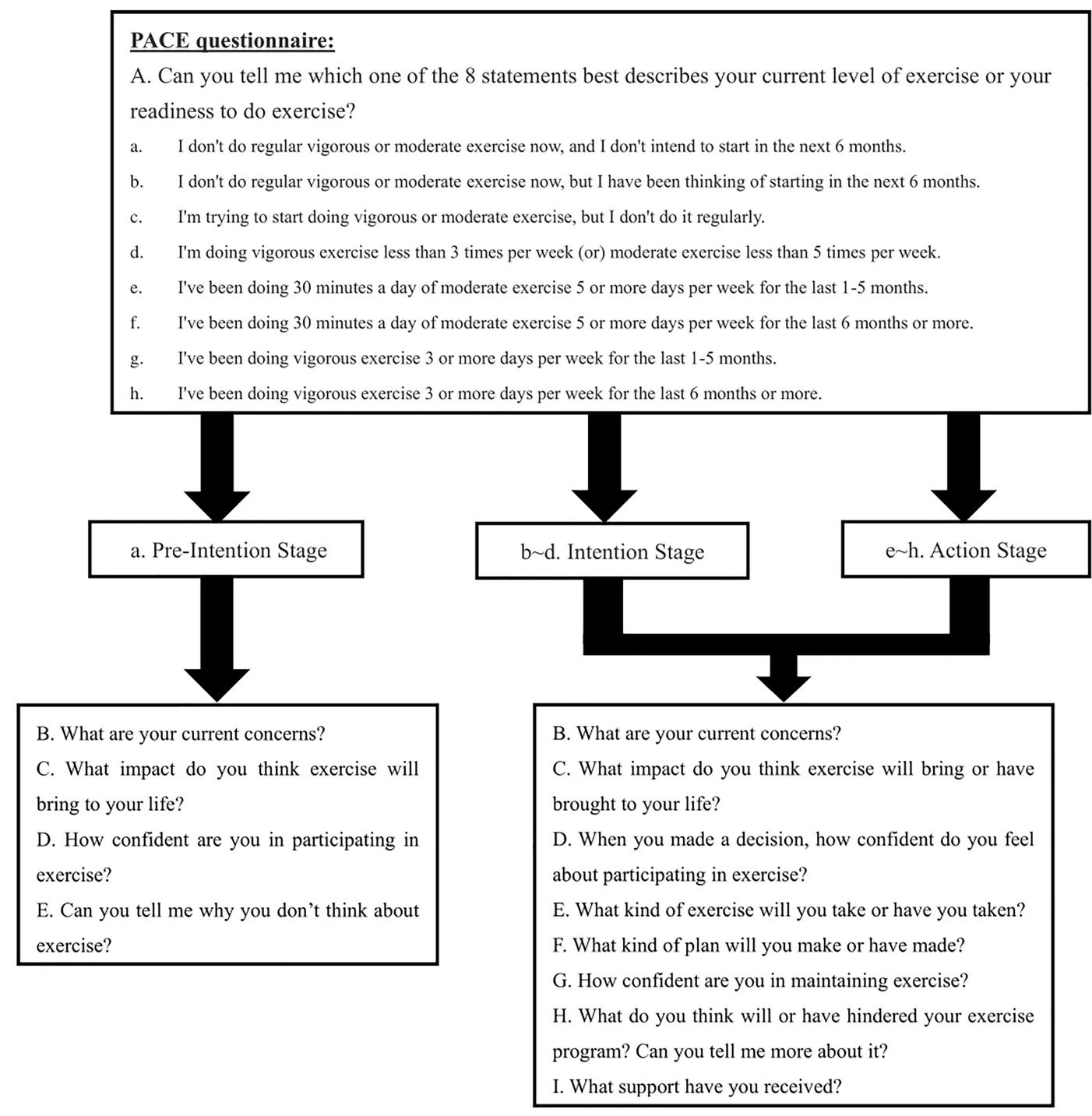

Fig. 2. Interview outline. The current state of patients is divided into pre-intention stage, intention stage and action stage according to the PACE questionnaire. In each stage, different questions are asked according to HAPA theory.

\subsection{Data analysis}

Directed content analysis was used for data analysis [24]. After face-to-face and telephone interviews with 24 patients, the data reached saturation. Within 24 hours after the interview, the researcher gradually converted the recordings into written materials that were then checked by another researcher. After the initial transcription, accuracy was ensured by repeatedly referring to the recording or by further communication with the participants. The materials were coded, sorted, and analyzed using NVivo 11 (QSR International Pty Ltd., Melbourne, VIC, Australia). Principles of confidentiality were strictly abided, and the interviewees were replaced by codes in the data analysis (P: Preintention stage; I: Intention stage; A: Action stage). The preliminary analysis was carried out by DNF. The research assistant checked the survey results and interview recordings and regularly discussed and reported with the research team members until a final consensus was reached.

Continuous variables are presented as mean \pm standard deviation or as median and interquartile range, depending on whether the variable conformed to a normal distribution. Data for independent samples were compared using the Student's $t$-test, analysis of variance, Mann-Whitney $\mathrm{U}$ test or Kruskal-Wallis H test, as appropriate. Categorical data are presented as numbers and percentages and were compared using the Chi-square test or Fisher's exact test. Post-hoc testing was used to evaluate differences between groups according to the adjusted standardized residual. Statistical significance was set at $p<0.05$ and data were analysed by SPSS version 24.0 for Windows (SPSS Inc., Chicago, IL, USA). 
Table 1. Patient demographic information.

\begin{tabular}{|c|c|c|c|c|c|}
\hline Demographic information & Pre-intention stage $(n=9)$ & Intention stage $(n=7)$ & Action stage $(\mathrm{n}=8)$ & $F / t / \chi^{2}$ & $p$ \\
\hline Age (years), mean $\pm \mathrm{SD}$ & $55.56 \pm 11.24$ & $50.14 \pm 12.66$ & $42.63 \pm 11.14$ & 2.627 & 0.096 \\
\hline \multicolumn{6}{|l|}{ Interview time interval (days), mean $\pm \mathrm{SD}$} \\
\hline Face-to-face interview & $14.80 \pm 16.96$ & $12.57 \pm 7.37$ & l & 0.276 & 0.794 \\
\hline Telephone interview & $405.25 \pm 165.23$ & / & $495.75 \pm 117.83$ & -1.104 & 0.295 \\
\hline Sex, n (\%) & & & & 1.138 & 0.720 \\
\hline Male & $7(77.8)$ & $6(85.7)$ & $5(62.5)$ & & \\
\hline Female & $2(22.2)$ & $1(14.3)$ & $3(37.5)$ & & \\
\hline Marital Status, n (\%) & & & & l & / \\
\hline Single & $0(0.0)$ & $0(0.0)$ & $0(0.0)$ & & \\
\hline Married & $9(100.0)$ & $7(100.0)$ & $8(100.0)$ & & \\
\hline Divorced or widowed & $0(0.0)$ & $0(0.0)$ & $0(0.0)$ & & \\
\hline Occupational status, n (\%) & & & & 5.471 & 0.124 \\
\hline Full-time work & $5(55.6)$ & $7(100.0)$ & $7(87.5)$ & & \\
\hline Unemployed & $1(11.1)$ & $0(0.0)$ & $1(12.5)$ & & \\
\hline Retired & $3(33.3)$ & $0(0.0)$ & $0(0.0)$ & & \\
\hline Highest level of education completed, n (\%) & & & & 7.156 & 0.315 \\
\hline Primary school & $3(33.3)$ & $1(14.3)$ & $1(12.5)$ & & \\
\hline Junior high school & $4(44.4)$ & $4(57.1)$ & $1(12.5)$ & & \\
\hline High school & $1(11.1)$ & $2(28.6)$ & $3(37.5)$ & & \\
\hline College and above & $1(11.1)$ & $0(0.0)$ & $3(37.5)$ & & \\
\hline Living alone, $\mathrm{n}(\%)$ & $1(11.1)$ & $0(0.0)$ & $0(0.0)$ & 1.683 & 1.000 \\
\hline Residential address, $\mathrm{n}(\%)$ & & & & 5.250 & 0.295 \\
\hline Urban district & $1(11.1)$ & $1(14.3)$ & $4(50.0)$ & & \\
\hline Town & $3(33.3)$ & $2(28.6)$ & $3(37.5)$ & & \\
\hline Countryside & $5(55.6)$ & $4(57.1)$ & $1(12.5)$ & & \\
\hline Length of stay (days), mean \pm SD & $25.67 \pm 22.53$ & $17.00 \pm 4.36$ & $16.88 \pm 10.99$ & 11.841 & 0.560 \\
\hline History of previous cardiac surgery, $\mathrm{n}(\%)$ & $7(77.8)$ & $1(14.3)$ & $3(37.5)$ & 6.417 & 0.043 \\
\hline Classification of aortic dissection, $\mathrm{n}(\%)$ & & & & 0.393 & 1.000 \\
\hline Type A aortic dissection & $4(44.4)$ & $4(57.1)$ & $4(50.0)$ & & \\
\hline Type B aortic dissection & $5(55.6)$ & $3(42.9)$ & $4(50.0)$ & & \\
\hline Type of operation, n (\%) & & & & 1.712 & 0.504 \\
\hline Interventional therapy & $6(66.7)$ & $3(42.9)$ & $6(75.0)$ & & \\
\hline Surgical operation & $3(33.3)$ & $4(57.1)$ & $2(25.0)$ & & \\
\hline
\end{tabular}


Table 1. Continued.

\begin{tabular}{|c|c|c|c|c|c|}
\hline Demographic information & Pre-intention stage $(\mathrm{n}=9)$ & Intention stage $(\mathrm{n}=7)$ & Action stage $(\mathrm{n}=8)$ & $F / t / \chi^{2}$ & $p$ \\
\hline \multicolumn{6}{|l|}{ Past history, $\mathrm{n}(\%)$} \\
\hline Hypertension & $6(66.7)$ & $5(71.4)$ & $5(62.5)$ & 0.303 & 1.000 \\
\hline Heart disease & $2(22.2)$ & $0(0.0)$ & $2(25.0)$ & 1.939 & 0.502 \\
\hline Kidney disease & $1(11.1)$ & $0(0.0)$ & $0(0.0)$ & 1.683 & 1.000 \\
\hline Lung disease & $2(22.2)$ & $1(14.3)$ & $0(0.0)$ & 1.872 & 0.609 \\
\hline Digestive system diseases & $2(22.2)$ & $1(14.3)$ & $0(0.0)$ & 1.872 & 0.609 \\
\hline Obesity & $0(0.00)$ & $1(14.3)$ & $0(0.0)$ & 2.185 & 0.292 \\
\hline Other & $0(0.00)$ & $1(14.3)$ & $0(0.0)$ & 2.185 & 0.292 \\
\hline \multicolumn{6}{|l|}{ Medications, n (\%) } \\
\hline Statin & $4(44.4)$ & $4(57.1)$ & $6(75.0)$ & 1.639 & 0.515 \\
\hline Aspirin & $2(22.2)$ & $2(28.6)$ & $2(25.0)$ & 0.327 & 1.000 \\
\hline Warfarin & $1(11.1)$ & $1(14.3)$ & $2(25.0)$ & 0.819 & 0.810 \\
\hline Antihypertensives & $9(100.0)$ & $6(85.7)$ & $7(87.5)$ & 1.614 & 0.511 \\
\hline Other antiplatelet agents & $1(11.1)$ & $0(0.0)$ & $0(0.0)$ & 1.683 & 1.000 \\
\hline Type of interview, n (\%) & & & & 16.000 & $<0.001$ \\
\hline Face-to-face & $5(55.6)$ & $7(100.0)$ & $0(0.0)$ & & \\
\hline Telephone & $4(44.4)$ & $0(0.0)$ & $8(100.0)$ & & \\
\hline Patient classification, n (\%) & & & & 22.690 & $<0.001$ \\
\hline In-patients without a history of cardiac surgery & $1(11.1)$ & $6(85.7)$ & $0(0.0)$ & & \\
\hline In-patients with a history of cardiac surgery & $6(66.7)$ & $1(14.3)$ & $0(0.0)$ & & \\
\hline Discharged patients without a history of cardiac surgery & $1(11.1)$ & $0(0.0)$ & $5(62.5)$ & & \\
\hline Discharged patients with a history of cardiac surgery & $1(11.1)$ & $0(0.0)$ & $3(37.5)$ & & \\
\hline
\end{tabular}

Note: the interview time interval was classified into two groups according to the type of interview. In-patients (i.e., face-to-face interviewers) were analysed according to the difference between the interview date and operation date, while discharged patients (i.e., telephone interviews) were analysed according to the difference between the interview date and the discharge date. 


\subsection{Ethics}

Informed written consent was collected from all participants in the study. The study was conducted in accordance with the Declaration of Helsinki [25] and was approved by the Medical Ethics Committee of the Tongji Medical College, Huazhong University of Science \& Technology, China (approval number: TJ-IRB20191221).

\section{Results}

\subsection{Demographic characteristics}

Table 1 shows the patient demographics and relevant factors for $\mathrm{AD}$ according to the different stages of behavior. A total of $24 \mathrm{AD}$ patients who met the inclusion criteria were included in the study. The mean age of patients was $49.67 \pm 12.42$ years, with $75 \%$ men and $25 \%$ women. Interventional therapy was performed in $15(62.5 \%)$ and surgical operation in $9(37.5 \%)$. Of the 24 participants interviewed, $9(37.5 \%)$ were in the pre-intention stage, $8(33.3 \%)$ were in the intention stage, and $7(29.2 \%)$ were in the action stage. Eleven patients $(45.83 \%)$ had a history of previous cardiac surgery. Of these, $8(63.6 \%)$ were re-entry patients in which subsequent physical examination showed the dissection had recurred. The remaining 3 patients had undergone previous stent surgery for coronary heart disease. The three groups were significantly different in terms of history of previous cardiac surgery (Fisher's exact test, $p=$ 0.043 ) and in the type of interview conducted (Fisher's exact test, $p<0.001)$. The patients were further divided into four groups according to whether they were in-patients or discharged, and whether or not they had a history of previous cardiac surgery. Significant differences were found between these groups (Fisher's exact test, $p<0.001$ ): inpatients without a history of cardiac surgery showed a preference for the intention stage, in-patients with a history of cardiac surgery showed a preference for the pre-intention stage, while discharged patients without a history of cardiac surgery showed a preference for the action stage (post-hoc test, $p<0.05$ ). Table 2 shows the general population distribution for each structure.

\subsection{Motivational phase constructs}

In the motivation phase constructs, individuals move from no behavior intention to the formation of behavioral intention and finally to take action. Table 3 shows some of the views of patients at different stages with regard to risk perception, outcome expectation, action self-efficacy and intention. These all appear in patients at the pre-intention, intention and action stages.

\subsubsection{Risk perception}

Risk perception refers to the overall evaluation of the potential severity and controllability of the disease, as well as the possibility that patients with $\mathrm{AD}$ are at risk for recurring events upon exercise participation [26]. The results showed that $\mathrm{AD}$ patients in the pre-intention stage were more likely to express risk perception, and that patients in the action stage had less risk perception (post-hoc test, $p$ $<0.05)$. The pre-intention and intention stage AD patients were more concerned about the adverse effects of disease compared to the action stage AD patients who already exercised. The patients in the pre-intention stage were more worried about postoperative pain and the impact on life and finances. Four of the 7 patients in the intention stage were more worried about their recovery after operation and expressed some fear of accidents during exercise. However, AD patients who had experienced AD events previously (i.e., re-entry patients) were most concerned about a recurrence of dissection, independently of exercise.

\subsubsection{Outcome expectations}

Outcome expectations indicate a comprehensive balance of the possible consequences of exercise in patients with $\mathrm{AD}$, including positive outcome expectations as well as negative outcome expectations [27]. Patients in the preintention stage were more likely to express negative results for exercise, while patients in the action stage tended to express positive results (post-hoc test, $p<0.05$ ). Patients in both the intention and action stages believed that physical activity and exercise were beneficial for them. Compared to patients in the intention stage, patients in the action stage identified different and more specific positive outcome expectations, including: (1) positive emotions, (2) self-confidence, and (3) family benefits. However, 5 out of 9 patients in the pre-intention stage also reported some negative outcome expectations. These included requiring great effort, worrying about accidents, increased family concerns, and feeling a psychological loss when the expected goal of exercise was not achieved.

\subsubsection{Action self-efficacy}

Action self-efficacy refers to the patients' confidence in their own ability when they begin exercise [28]. There was a large difference in action self-efficacy between patients in the pre-intention stage compared to the other two groups. The action self-efficacy of patients in the preintention stage was often low (post-hoc test, $p<0.05$ ). Patients in both the intention and action stages had a high level of action self-efficacy when they decided to start exercising. However, the self-efficacy of action was low in patients in the pre-intention stage due to an unwillingness to try, poor compliance, and for other reasons.

\subsubsection{Intentions}

Patients in the pre-intention stage were found to often lack the intention of exercise, while patients in the action stage have a clear intention to participate in physical activities and to exercise (post-hoc test, $p<0.05$ ). Reasons for the lack of exercise intention in pre-intention stage patients was mainly due to: (1) symptoms of discomfort, (2) lack of confidence, (3) poor compliance, and (4) their family's overprotection. 
Table 2. Structural distribution characteristics.

\begin{tabular}{lcccccc}
\hline & $\begin{array}{c}\text { Total number } \\
(\mathrm{n}=24)\end{array}$ & $\begin{array}{c}\text { Pre-intention } \\
\text { stage }(\mathrm{n}=9)\end{array}$ & $\begin{array}{c}\text { Intention stage } \\
(\mathrm{n}=7)\end{array}$ & $\begin{array}{c}\text { Action stage } \\
(\mathrm{n}=8)\end{array}$ & $\chi^{2}$ & $p$ \\
\hline Risk perception, n (\%) & $11(45.8)$ & $7(77.8)$ & $4(57.1)$ & $0(0.0)$ & 11.249 & 0.003 \\
Positive outcome expectations, n (\%) & $18(75.0)$ & $3(33.3)$ & $7(100.0)$ & $8(100.0)$ & 11.386 & 0.001 \\
Negative outcome expectations, n (\%) & $5(20.8)$ & $5(55.6)$ & $0(0.0)$ & $0(0.0)$ & 8.526 & 0.005 \\
Action self-efficacy, n (\%) & $9(37.5)$ & $0(0.0)$ & $4(57.1)$ & $5(62.5)$ & 9.187 & 0.008 \\
Intentions, n (\%) & $11(45.8)$ & $0(0.0)$ & $5(71.4)$ & $6(75.0)$ & 12.773 & 0.001 \\
Implementation intention & & & & & \\
$\quad$ Action planning, n (\%) & $12(50.0)$ & $0(0.0)$ & $4(57.1)$ & $8(100.0)$ & 18.562 & $<0.001$ \\
$\quad$ Coping planning, $\mathrm{n}(\%)$ & $2(8.3)$ & $0(0.0)$ & $0(0.0)$ & $2(25.0)$ & 3.000 & 0.178 \\
Maintenance self-efficacy, $\mathrm{n}(\%)$ & $13(54.2)$ & $0(0.0)$ & $5(71.4)$ & $8(100.0)$ & 19.438 & $<0.001$ \\
Recovery self-efficacy, $\mathrm{n}(\%)$ & $1(4.2)$ & $0(0.0)$ & $0(0.0)$ & $1(12.5)$ & 1.918 & 0.625 \\
Barriers, n (\%) & $11(45.8)$ & $4(44.4)$ & $3(42.9)$ & $4(50.0)$ & 0.247 & 1.000 \\
Promoting factors, $\mathrm{n}(\%)$ & $12(50.0)$ & $3(33.3)$ & $4(57.1)$ & $5(62.5)$ & 1.650 & 0.589 \\
\hline
\end{tabular}

\subsection{Volitional phase constructs}

In the volitional phase constructs, individuals make plans, overcome the difficulties encountered in action and adjust themselves, so as to adhere to action and finally develop healthy behavior. Patients in the pre-intention stage had not yet experienced the volitional phase. Therefore, this stage only focused on patients in the intention stage and action stage. Table 4 shows some patient views with regard to implementation intention, maintenance self-efficacy and recovery self-efficacy.

\subsubsection{Implementation intention}

Implementation intention includes action planning and coping planning [29]. Action planning for patients in the pre-intention stage had not been developed, whereas patients in the action stage had a clear action plan (post-hoc test, $p<0.05)$. Four of the 7 patients in intention stage and all patients in action stage had clear action planning. Walking was found to be the most popular exercise for AD patients $(50 \%)$. Other activities included square dancing, fast walking, fitness and jogging. Three of the 7 patients in intention stage had not yet thought about action planning. Only two of the 8 patients in action stage said they had developed coping strategies. Coping strategies include: (1) recording, and (2) finding new ways.

\subsubsection{Maintenance self-efficacy}

Maintenance self-efficacy refers to the optimistic belief of patients with $\mathrm{AD}$ in coping with difficulties during maintenance exercise [19]. The maintenance efficacy of patients in the pre-intention stage was found to be lower, while patients in the action stage had higher maintenance self-efficacy (post-hoc test, $p<0.05$ ). Five of the 7 patients in intention stage and all patients in action stage felt confident to maintain exercise participation. Positive feedback was the most important factor for maintaining self-efficacy. Just 2 of the 7 patients in intention stage worried that they could not adhere to an exercise program.

\subsubsection{Recovery self-efficacy}

Recovery self-efficacy refers to the ability of AD patients to overcome obstacles when they do not carry out the exercise plan on schedule [30]. Most patients in the intention and action stages claimed that the biggest task after discharge was to take care of their body and they would always adhere to appropriate activities. Only one of the 24 patients experienced a period of interrupted exercise, but they then overcame the obstacles and resumed regular exercise.

\subsection{Additional important constructs}

In addition to the above constructs, HAPA also recognizes that barriers and facilitators can also affect an individual's behavioral intention [31]. Table 5 shows some views of patients at different stages on barriers and promoting factors of exercise.

\subsubsection{Barriers}

Almost half of patients $(11 / 24,45.8 \%)$ described the presence of barriers to exercise: (1) financial problems, (2) attitudes of family members, and (3) environmental factors. Three out of 11 patients expressed great concern about financial problems. The families of three out of 11 patients thought that accidents might occur during exercise and thus did not support it. Weather conditions were also factors that stopped patients from carrying out exercise.

\subsubsection{Promoting factors}

Half the patients $(12 / 24)$ expressed that various promoting factors increased their ability to support exercise participation, including (1) personal interest, (2) support from other patients and from their families, and (3) the encouragement of medical staff. The patients' enthusiasm and mental state also affected their desire to participate in exercise. Two out of 12 patients indicated that the support of 
Table 3. Some patient views on the motivational phase constructs.

\begin{tabular}{|c|c|c|}
\hline Theme & Codes & Sample quotes \\
\hline \multirow[t]{4}{*}{ Risk perception } & Worried about recurrence of disease & $\begin{array}{l}\text { "I'm really afraid this disease will recur again. Over four years, I have suffered three times because of this } \\
\text { disease. I felt burdened because I was sick soon after my second child was born (...)." (Participant P2) }\end{array}$ \\
\hline & Worried about the postoperative pain & $\begin{array}{l}\text { "Before I was sent to hospital, I felt severe pain in my chest and back, and a sense of dying. Although the } \\
\text { operation had been done, I still felt very painful. The doctor told me to get out of bed and walk around, but I } \\
\text { didn't dare. This was a feeling I had never felt before." (Participant P5) }\end{array}$ \\
\hline & Worried about the impact on life and finances & $\begin{array}{l}\text { "I have undergone thoracotomy. Now I dare not get out of bed. My daily life needs are taken care of by my } \\
\text { family (...) I am very worried that I can't return to normal life after the operation." (Participant P5) } \\
\text { "The disease really costs a lot of money, my family has lost financially because I was ill (...) (Sighs, and turns } \\
\text { to the interviewers) It will cost a lot of money if I go to rehabilitation training, I don't think I can afford it." } \\
\text { (Participant P7) }\end{array}$ \\
\hline & $\begin{array}{l}\text { Worried about the recovery after operation } \\
\text { Afraid of accidents during exercise }\end{array}$ & $\begin{array}{l}\text { "We all know the operation is very risky. The doctors said the recovery after discharge was very important. I'm } \\
\text { still a bit worried because I don't know much about the rehabilitation. (...) I'm old, and I'm afraid of accidents } \\
\text { when I go out for a walk." (Participant I1) }\end{array}$ \\
\hline \multirow[t]{4}{*}{ Positive outcome expectations } & Perceived benefits & "I can keep fit through some low and medium intensity exercise, which is good for my health." (Participant I2) \\
\hline & Positive emotions & $\begin{array}{l}\text { "After I was just discharged from hospital, I felt a bit depressed. Later, I began to do public square dancing. I } \\
\text { made many friends of the same age as me, and my mood began to improve." (Participant A3) }\end{array}$ \\
\hline & Self-confidence & $\begin{array}{l}\text { "Just after the operation, I was worried that my body would be limited because I had always liked doing sport } \\
\text { before. But after recovering for some time, I could walk more than } 10000 \text { steps each day. Most of my life was } \\
\text { the same as before, which increased my self-confidence." (Participant A6) }\end{array}$ \\
\hline & Family benefits & "My wife was also very happy to see that I increased my activity each day." (Participant A4) \\
\hline \multirow[t]{4}{*}{ Negative outcome expectations } & Make great efforts & $\begin{array}{l}\text { "I've been in the hospital for a long time. Before I was hospitalized, I didn't exercise much because of my work. } \\
\text { I think exercising requires me to push myself and consumes a lot of time and energy." (Participant P1) }\end{array}$ \\
\hline & Accidents & $\begin{array}{l}\text { "The disease began suddenly and was a great blow to me. I'm not sure if there will be accidents during exercise, } \\
\text { which I'm afraid of." (Participant P4) }\end{array}$ \\
\hline & Increase family concerns & $\begin{array}{l}\text { "My family has been worried about my illness and recovery. If I go to exercise, I think it will increase their } \\
\text { worry." (Participant P3) }\end{array}$ \\
\hline & Feel a sense of loss & $\begin{array}{l}\text { "I feel my body is much worse than before I was ill (...) I will feel a sense of loss if my ability to exercise does } \\
\text { not reach the expected level." (Participant P6) }\end{array}$ \\
\hline
\end{tabular}




\section{Table 3. Continued.}

\begin{tabular}{|c|c|c|}
\hline Theme & Codes & Sample quotes \\
\hline \multirow[t]{2}{*}{ Action self-efficacy } & High action self-efficacy & $\begin{array}{l}\text { "It's a blow for me to suddenly get sick. I didn't like doing sport before. My wife would ask me to go out for a } \\
\text { walk but I didn't listen to her (...) but now I know that taking a walk every day is good for my body and mind, } \\
\text { so I'm confident I can stick with this after discharge." (Participant I3) }\end{array}$ \\
\hline & $\begin{array}{l}\text { Low action self-efficacy due to lack of Effort, } \\
\text { poor compliance and other reasons }\end{array}$ & "I'm really afraid of pain, so I don't have the confidence to try (...)." (Participant P5) \\
\hline \multirow[t]{3}{*}{ Intentions } & Lack of exercise intention due to symptoms of & "I feel chest tightness and poor breathing as soon as I move (...)." (Participant P3) \\
\hline & $\begin{array}{l}\text { discomfort, lack of confidence, poor complia- } \\
\text { nce, overprotection }\end{array}$ & $\begin{array}{l}\text { "After being in hospital for such a long time, I feel that my body is not like before, and I haven't recovered well } \\
\text { (...). I don't have the self-confidence to begin exercising, so I haven't started to think about it now." (Participant } \\
\text { P1) }\end{array}$ \\
\hline & & $\begin{array}{l}\text { "I think I'm recovering well now. I don't think I need to exercise. My family also told me not to over exercise. } \\
\text { I think it's good to sit (...) Now I just sit and play mahjong for four hours every day." (Participant P6) }\end{array}$ \\
\hline
\end{tabular}

The patients in pre-intention stage: P1, P2, P3 ...

The patients in intention stage: I1, I2, I3 ..

The patients in action stage: A1, A2, A3 ... 
Table 4. Some patient views on volitional phase constructs.

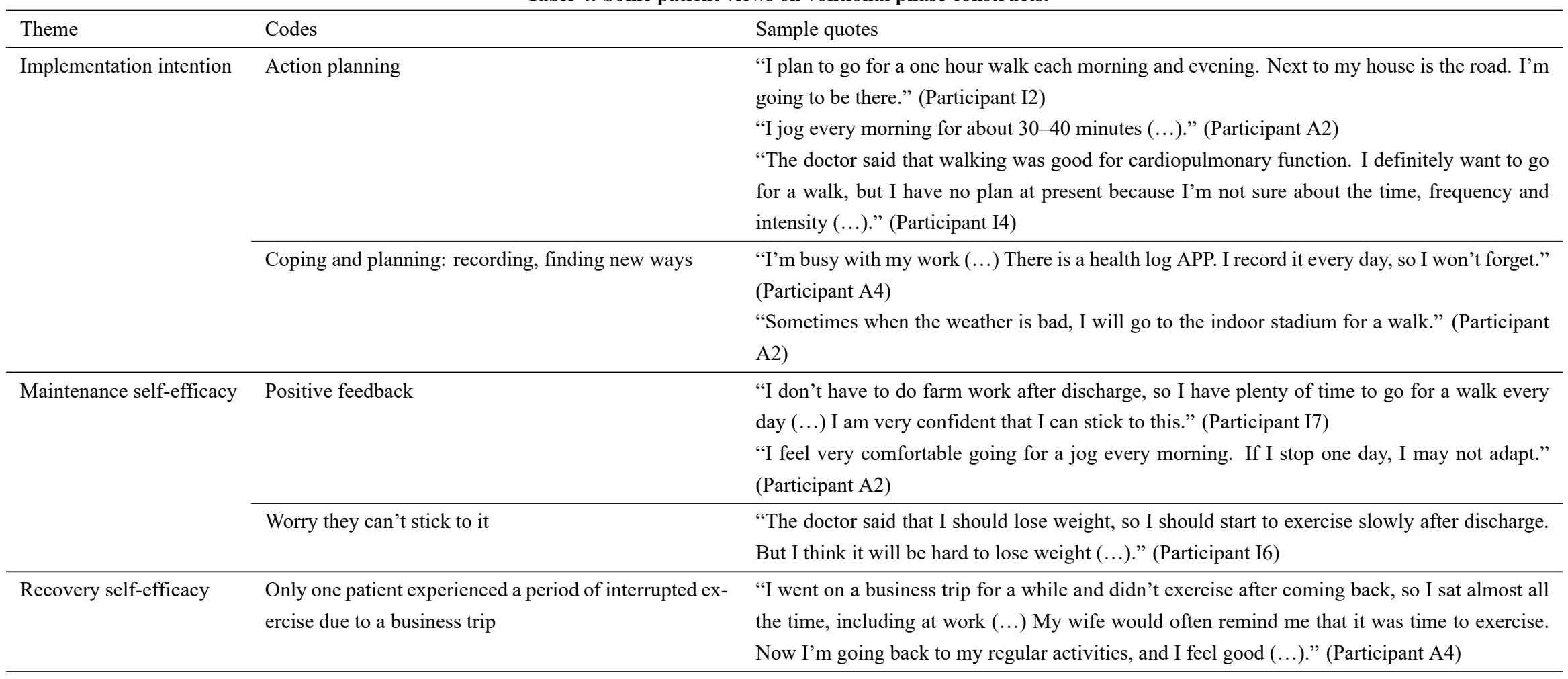

The patients in pre-intention stage: $\mathrm{P} 1, \mathrm{P} 2, \mathrm{P} 3 \ldots$

The patients in intention stage: I1, I2, I3 ...

The patients in action stage: A1, A2, A3 ... 
Table 5. Some views of patients on barriers and on promoting factors.

\begin{tabular}{|c|c|c|}
\hline Theme & Codes & Sample quotes \\
\hline \multirow[t]{3}{*}{ Barriers } & Finances & $\begin{array}{l}\text { "This operation cost our family a lot of money. Originally, my family was from the countryside (...) Now that } \\
\text { I have time to do some farm work and earn more money, there is no time to exercise." (Participant P7) }\end{array}$ \\
\hline & Attitudes of family members & $\begin{array}{l}\text { "I am usually at home alone, and my children work outside. They do not like that I go out alone for a walk, for } \\
\text { fear of accidents (...)." (Participant P9) }\end{array}$ \\
\hline & Environmental factor & $\begin{array}{l}\text { "Sometimes when it rains or snows, I don't want to go out and I prefer to watch TV at home (...)." (Participant } \\
\text { A3) }\end{array}$ \\
\hline \multirow[t]{3}{*}{ Promoting factors } & Personal interest & $\begin{array}{l}\text { "I usually like to exercise because it can improve my mood. Sometimes I feel like going for a long walk and } \\
\text { even though I feel a little uncomfortable, I believe I can do it." (Participant A5) }\end{array}$ \\
\hline & Support from others & $\begin{array}{l}\text { "I also have friends around me who have this disease. We have arranged to go for a walk after I leave the } \\
\text { hospital." (Participant I5) } \\
\text { "I have been hospitalized three times. Each time my husband has given me a lot of support. He encouraged me } \\
\text { to walk slowly until I could walk on my own (...) Now my situation is getting better each day and so I really } \\
\text { appreciate his support." (Participant A6) }\end{array}$ \\
\hline & Encouragement of medical staff & $\begin{array}{l}\text { "The doctor encouraged me to get out of bed and to walk as soon as I felt better (...) He also suggested that } \\
\text { I do some low to moderate intensity exercise after I leave the hospital and he encouraged me to lose weight." } \\
\text { (Participant I6) } \\
\text { "I added the doctor's WeChat contact information, so that he could give me some guidance." (Participant P4) }\end{array}$ \\
\hline
\end{tabular}

The patients in pre-intention stage: P1, P2, P3 ...

The patients in intention stage: I1, I2, I3 ...

The patients in action stage: A1, A2, A3 ... 
other patients could promote their compliance for physical activities. Three out of 12 patients expressed that family support is very important. The professional advice of medical staff also directly affected the enthusiasm and compliance of patients to participate in sports.

\section{Discussion}

This is the first qualitative study to explore the attitudes and behavioral intentions of AD survivors towards exercise. The following aspects were addressed: (1) use of the PACE questionnaire to classify the current stage of patients, (2) the use of HAPA theory to outline and conduct qualitative interviews, (3) comparison of the differences in HAPA constructs between patients from different stages.

Among the 24 participants interviewed, 9 (37.5\%) were in the pre-intention stage, $8(33.3 \%)$ were in the intention stage, and $7(29.2 \%)$ were in the action stage. In a study by Chaddha et al. [14], 62/82 (76\%) of AD survivors participated in structured physical activity, which was a higher rate than in our study. Our current study included both inhospital patients and discharged patients. Most of the hospitalized patients were still in the recovery stage and therefore rarely able to participate in exercise behavior. This may explain the difference in exercise participation rate between our study and that of Chaddha et al. [14]. Interestingly, we found that in-patients without a history of cardiac surgery showed a preference for the intention stage, whereas inpatients with a history of cardiac surgery showed a preference for the pre-intention stage. Therefore, medical staff should pay close attention to in-patients with a history of cardiac surgery. They should carefully explain health education to them, explain the benefits of exercise on the cardiovascular system, inform them of any precautions for exercise after discharge, and promote behavior intention and progress to the intention and action stages.

The present study found that AD survivors in the preintention and intention stages expressed more risk perception and concerns about the adverse effects of disease, including recurrence, pain, the impact on life and finances, postoperative rehabilitation and accidents during exercise. This was consistent with the findings of Chadha's study, in which $76 \%$ of $\mathrm{AD}$ patients believed the disease had a negative impact on their lives [9]. New dissection, organ ischemia, aneurysm formation or rupture may occur after $\mathrm{AD}$ operation $[1,32,33]$. Depression and anxiety were more common in AD survivors than in other heart disease survivors [9]. Chaddha et al. [14] also pointed out that fear was the main reason that most survivors limited their activities.

Of interest, the results also showed that outcome expectations were different for different stages. Action stage patients often had more positive outcome expectations, while pre-intention stage patients had more negative outcome expectations. Previous studies have reported that outcome expectations play a significant role in predicting be- havioral intention, mainly in the intention formation stage. The more positive expectations an individual has about taking a certain health promotion behavior or giving up a certain health hazard behavior, the more favorable the formation of behavior intention [27].

We also explored the reasons underlying different intention performance for different stages. The reasons why exercise was often not considered in the pre-intention stage included discomfort, lack of self-confidence, poor compliance and family overprotection. This was consistent with the findings of other related studies [34,35]. Implementation intention is the further concretization of intention [36] and can promote the effective transformation from intention to actual behavior [29]. In the intention and action stages of $\mathrm{AD}$ patients, the main exercise methods are walking, fitness, square dancing and jogging. However, some patients in the intention stage were unable to organize the frequency, time and intensity of exercise. Surprisingly, only 2 of the 24 patients in this study had coping plans. Previous studies have shown that exercise is safe for patients with AD and there are no serious complications [12,37-39]. However, there is still a lack of guidance regarding the appropriate level, type, frequency, intensity, and duration of physical activity. Therefore, it seems timely to establish guidelines based on the available data for exercise in AD patients. This should provide some guidance to physicians and patients for organizing and performing exercise after an AD event.

Self-efficacy can be divided into action self-efficacy, maintenance self-efficacy and recovery self-efficacy [28]. Self-efficacy can predict behavioral intention, as well as predicting behavior change in the next stage [30]. This study showed that action self-efficacy was present in all three stages, whereas the structure of maintaining selfefficacy and recovery self-efficacy existed only in the intention and action stages. A previous study found that selfefficacy can affect the choice of activities, the level of effort and perseverance in the face of difficulties [40]. The current finding also suggests that regardless of the type of self-efficacy, the action stage tended to show more positivity and thus higher exercise compliance.

Various barriers were expressed in this study, including the lack of time and opportunity to exercise, concern about accidents, and bad weather preventing outdoor exercise. Previous studies have reported that illness or injury, work commitments, and poor weather are key barriers to exercise $[41,42]$. In contrast, favorable factors for the promotion of exercise behavior included personal interest, support from others, and encouragement by medical staff. The recommendation by medical staff was previously identified as an important factor to improve the behavior compliance of patients $[43,44]$. Our research also found that the attitude of family members can have a significant positive impact on the enthusiasm and compliance of patients to participate in exercise. Conversely, however, family members may also hinder exercise behavior. 


\section{Conclusions}

This study explored the attitude and behavior intention of AD patients in different behavior stages based on HAPA theory. In-patients with a history of cardiac surgery showed a preference for the pre-intention stage. Moreover, patients from different stages had different structures. For example, AD patients in the pre-intention stage were more likely to express risk perception and have negative results for exercise. The self-efficacy of this group was often low and lacking in exercise intention and clear action plans (posthoc test, $p<0.05$ ). Therefore, more attention should be given to in-patients with a history of cardiac surgery. This could include more health education regarding exercise after discharge and the promotion of changes in their health behavior. This study provides direction for understanding the relationship between different variables and for predicting the process of exercise behavior change. The results also provide supporting evidence and effective evaluation tools for exercise rehabilitation intervention in $\mathrm{AD}$ patients. However, this study was conducted in a single center only and with a relatively small sample size. Its purpose was to understand the cognition, attitude and intention of $\mathrm{AD}$ patients to exercise through qualitative research. The variables of "history of previous cardiac surgery" and "type of interview conducted (i.e., in-patient or discharged patient)" were statistically significant in each of the three different stages. Future work should use a quantitative questionnaire designed for a study involving multiple centers to predict the exercise intention of AD patients. This should allow a more comprehensive understanding of the factors influencing behavior intention, thus providing a basis for promoting patient rehabilitation and improving their postoperative quality of life.

\section{Author contributions}

DNF - conception of the study, major drafting of the work, final approval and agreeing to the accuracy of the work. SFH - conception of the study, help in design of the study, drafting of the work, final approval and agreeing to the accuracy of the work. XRL-supervision, critical revision of the manuscript, final approval and agreeing to the accuracy of the work. All authors contributed to editorial changes in the manuscript. All authors read and approved the final manuscript.

\section{Ethics approval and consent to participate}

Informed written consent was collected from all participants in the study. The study was conducted in accordance with the Declaration of Helsinki and was approved by the Medical Ethics Committee of the Tongji Medical College, Huazhong University of Science \& Technology, China (approval number: TJ-IRB20191221).

\section{Acknowledgment}

Thanks to all the peer reviewers for their opinions and suggestions.

\section{Funding}

This research was funded by National Natural Science Foundation of China, grant number: Project 71874063.

\section{Conflict of interest}

The authors declare no conflict of interest.

\section{References}

[1] Erbel R, Aboyans V, Boileau C, Bossone E, Bartolomeo RD, Eggebrecht H, et al. 2014 ESC Guidelines on the diagnosis and treatment of aortic diseases: Document covering acute and chronic aortic diseases of the thoracic and abdominal aorta of the adult. The Task Force for the Diagnosis and Treatment of Aortic Diseases of the European Society of Cardiology (ESC). European Heart Journal. 2014; 35: 2873-2926.

[2] Elghannam M, Aljabery Y, Naraghi H, Moustafine V, Bechte M, Strauch J, et al. Minimally invasive aortic root surgery: Midterm results in a 2-year follow-up. Journal of Cardiac Surgery. 2020; 35: 1484-1491.

[3] Li H, Yu H, Dong N, Wu L. A Modified Hypothermic Circulatory Arrest Technique Improves Early and Near-Midterm Results in Patients with Acute Type A Aortic Dissection. The Heart Surgery Forum. 2021; 24: E675-E679.

[4] Howard DPJ, Banerjee A, Fairhead JF, Perkins J, Silver LE, Rothwell PM. Population-based study of incidence and outcome of acute aortic dissection and premorbid risk factor control: 10year results from the Oxford Vascular Study. Circulation. 2013; 127: 2031-2037.

[5] Koullias G, Modak R, Tranquilli M, Korkolis DP, Barash P, Elefteriades JA. Mechanical deterioration underlies malignant behavior of aneurysmal human ascending aorta. The Journal of Thoracic and Cardiovascular Surgery. 2005; 130: 677-683.

[6] Ghazy T, Eraqi M, Mahlmann A, Hegelmann H, Matschke K, Kappert U, et al. Quality of Life after Surgery for Stanford Type A Aortic Dissection: Influences of Different Operative Strategies. The Heart Surgery Forum. 2017; 20: E102-E106.

[7] Endlich M, Hamiko M, Gestrich C, Probst C, Mellert F, Winkler K, et al. Long-Term Outcome and Quality of Life in Aortic Type a Dissection Survivors. The Thoracic and Cardiovascular Surgeon. 2016; 64: 91-99.

[8] Olsson C, Franco-Cereceda A. Health-Related Quality of Life in Thoracic Aortic Disease: Part I. Cases Managed Nonoperatively. Aorta. 2013; 1: 153-161.

[9] Chaddha A, Kline-Rogers E, Braverman AC, Erickson SR, Jackson EA, Franklin BA, et al. Survivors of Aortic Dissection: Activity, Mental Health, and Sexual Function. Clinical Cardiology. 2015; 38: 652-659.

[10] Adam U, Habazettl H, Graefe K, Kuppe H, Wundram M, Kurz SD. Health-related quality of life of patients after surgery for acute Type A aortic dissection. Interactive Cardiovascular and Thoracic Surgery. 2018; 27: 48-53.

[11] Mussa FF, Horton JD, Moridzadeh R, Nicholson J, Trimarchi S, Eagle KA. Acute Aortic Dissection and Intramural Hematoma: A Systematic Review. The Journal of the American Medical Association. 2016; 316: 754-763.

[12] Fuglsang S, Heiberg J, Hjortdal VE, Laustsen S. Exercise-based cardiac rehabilitation in surgically treated type-A aortic dissection patients. Scandinavian Cardiovascular Journal. 2017; 51: 99-105. 
[13] Anderson L, Oldridge N, Thompson DR, Zwisler A, Rees K, Martin N, et al. Exercise-Based Cardiac Rehabilitation for Coronary Heart Disease: Cochrane Systematic Review and MetaAnalysis. Journal of the American College of Cardiology. 2016; 67: 1-12.

[14] Chaddha A, Eagle KA, Braverman AC, Kline-Rogers E, Hirsch AT, Brook R, et al. Exercise and Physical Activity for the PostAortic Dissection Patient: The Clinician's Conundrum. Clinical Cardiology. 2015; 38: 647-651.

[15] Abdelbasset WK, Alqahtani BA. A randomized controlled trial on the impact of moderate-intensity continuous aerobic exercise on the depression status of middle-aged patients with congestive heart failure. Medicine. 2019; 98: e15344.

[16] Feng D, Ke J, Huang S, Lang X. A scoping review of exercisebased cardiac rehabilitation for patients with aortic dissection. Reviews in Cardiovascular Medicine. 2021; 22: 613-624.

[17] Chaddha A, Kline-Rogers E, Woznicki EM, Brook R, Housholder-Hughes S, Braverman AC, et al. Cardiology patient page. Activity recommendations for postaortic dissection patients. Circulation. 2014; 130: e140-e142.

[18] Perreault K. Research Design: Qualitative, Quantitative, and Mixed Methods Approaches. Manual Therapy. 2011; 16: 103.

[19] Schwarzer, R. Self-Efficacy through Control of Action. 1st edn. Hemisphere Publishing Corporation: Washington, DC, USA. 1992.

[20] Meade LB, Bearne LM, Godfrey EL. "it's important to buy in to the new lifestyle": barriers and facilitators of exercise adherence in a population with persistent musculoskeletal pain. Disability and Rehabilitation. 2021; 43: 468-478.

[21] Crandall K, Maguire R, Campbell A, Kearney N. A qualitative study exploring the views, attitudes and beliefs of patients and health professionals towards exercise intervention for people who are surgically treated for lung cancer. European Journal of Cancer Care. 2018; 27: e12828.

[22] Saunders B, Sim J, Kingstone T, Baker S, Waterfield J, Bartlam $\mathrm{B}$, et al. Saturation in qualitative research: exploring its conceptualization and operationalization. Quality \& Quantity. 2018; 52: 1893-1907.

[23] Ainsworth BE, Youmans CP. Tools for physical activity counseling in medical practice. Obesity Research. 2002; 10: 69S-75S.

[24] Elo S, Kyngäs H. The qualitative content analysis process. Journal of Advanced Nursing. 2008; 62: 107-115.

[25] World Medical Association. World Medical Association Declaration of Helsinki: ethical principles for medical research involving human subjects. The Journal of the American Medical Association. 2013; 310: 2191-2194.

[26] Becker M. The health belief model and personal health behavior. Health Education Monographs. 1974; 2: 324-473.

[27] Williams DM, Anderson ES, Winett RA. A review of the outcome expectancy construct in physical activity research. Annals of Behavioral Medicine. 2005; 29: 70-79.

[28] Marlatt, GA, Baer JS, Quigley LA. Self-efficacy and addictive behavior. In: Bandura A, editor. Self-efficacy in changing societies. Cambridge University Press: New York. 1995. p. 289315.

[29] Schüz B, Sniehotta FF, Wiedemann A, Seemann R. Adherence to a daily flossing regimen in university students: effects of planning when, where, how and what to do in the face of barriers.
Journal of Clinical Periodontology. 2006; 33: 612-619.

[30] Schwarzer R. Modeling Health Behavior Change: how to Predict and Modify the Adoption and Maintenance of Health Behaviors. Applied Psychology. 2008; 57: 1-29.

[31] Schwarzer R, Lippke S, Luszczynska A. Mechanisms of health behavior change in persons with chronic illness or disability: the Health Action Process Approach (HAPA). Rehabilitation Psychology. 2011; 56: 161-170.

[32] Pagni S, Ganzel BL, Trivedi JR, Singh R, Mascio CE, Austin $\mathrm{EH}$, et al. Early and midterm outcomes following surgery for acute type A aortic dissection. Journal of Cardiac Surgery. 2013; 28: 543-549.

[33] Luebke T, Brunkwall J. Type B Aortic Dissection: a Review of Prognostic Factors and Meta-analysis of Treatment Options. Aorta. 2014; 2: 265-278.

[34] Paguntalan JC, Gregoski M. Physical activity barriers and motivators among high-risk employees. Work. 2016; 55: 515-524.

[35] Rogerson MC, Murphy BM, Bird S, Morris T. "I don't have the heart": a qualitative study of barriers to and facilitators of physical activity for people with coronary heart disease and depressive symptoms. International Journal of Behavioral Nutrition and Physical Activity. 2012; 9: 140.

[36] Gollwitzer PM. Implementation intentions: Strong effects of simple plans. American Psychologist. 1999; 54: 493-503.

[37] Delsart P, Delahaye C, Devos P, Domanski O, Azzaoui R, Sobocinski J, et al. Prognostic value of aerobic capacity and exercise oxygen pulse in postaortic dissection patients. Clinical Cardiology. 2021; 44: 252-260.

[38] Hornsby WE, Norton EL, Fink S, Saberi S, Wu X, McGowan CL, et al. Cardiopulmonary Exercise Testing Following Open Repair for a Proximal Thoracic Aortic Aneurysm or Dissection. Journal of Cardiopulmonary Rehabilitation and Prevention. 2020; 40: 108-115.

[39] Corone S, Iliou M, Pierre B, Feige J, Odjinkem D, Farrokhi T, et $a l$. French registry of cases of type I acute aortic dissection admitted to a cardiac rehabilitation center after surgery. European Journal of Cardiovascular Prevention \& Rehabilitation. 2009; 16: 91-95.

[40] Bandura A, Freeman WH, Lightsey R. Self-efficacy: the exercise of control. Journal of Cognitive Psychotherapy. 1997; 13: 158.

[41] Tulloch H, Sweet SN, Fortier M, Capstick G, Kenny GP, Sigal RJ, et al. Exercise facilitators and barriers from adoption to maintenance in the diabetes aerobic and resistance exercise trial. Canadian Journal of Diabetes. 2013; 37: 367-374.

[42] Clark AM, King-Shier KM, Spaling MA, Duncan AS, Stone JA, Jaglal SB, et al. Factors influencing participation in cardiac rehabilitation programmes after referral and initial attendance: qualitative systematic review and meta-synthesis. Clinical Rehabilitation. 2013; 27: 948-959.

[43] Beswick AD, Rees K, West RR, Taylor FC, Burke M, Griebsch I, et al. Improving uptake and adherence in cardiac rehabilitation: literature review. Journal of Advanced Nursing. 2005; 49: 538 555.

[44] Balady GJ, Ades PA, Bittner VA, Franklin BA, Gordon NF, Thomas RJ, et al. Referral, Enrollment, and Delivery of Cardiac Rehabilitation/Secondary Prevention Programs at Clinical Centers and beyond. Circulation. 2011; 124: 2951-2960. 